\title{
Zé Do Caixão y el gótico brasileño de José Mojica Marins.
}

\section{Zé do Caixão: José Mojica Marins’s Brazilian Gothic.}

\section{Resumen}

Se destacan aquí conexiones entre el personaje brasileño, Zé do Caixão, y la tradición gótica por medio de apropiaciones culturales que son utilizadas por el director José Mojica Marins como un método de asociación del personaje a renombrados iconos de terror. El uso de tal conjunto de representaciones asociadas al gótico (trajes, ángulos de cámara, iluminación, accesorios, mise-en-scène) constituye un sistema de significados simbólicos en que la autopresentación se convierte en un ingrediente esencial para producir el efecto de terror. Al mismo tiempo, la presencia de tales elementos evidencia una dimensión política, una forma de alegorización de situaciones históricas que no podían ser fácilmente comprendidas o que podrían abordarse con mayor eficacia si fueran transportadas a un mundo de fantasía. Mojica se aprovecha del hecho de que la violencia, tortura y representación de las fuerzas tiránicas en general son constitutivas del género de terror para dar una respuesta estética a la sociedad de su tiempo en forma de una representación histórica del contexto violento de la dictadura militar brasileña. La aclimatación de elementos extranjeros insertada en el contexto socio-cultural de las producciones nacionales constituye lo que se llamó aquí «gótico brasileño».

Palabras claves

Zé do Caixão, José Mojica Marins, Gótico, Dictadura Militar en Brasil.

\begin{abstract}
This article highlights links between Brazilian character Zé do Caixão and the Gothic tradition by means of cultural appropriations used by director José Mojica Marins as a method of associating the character with renowned horror icons. The use of such a set of representations which are associated with Gothic (costumes, camera angles, lighting, props, mise-en-scène) constitutes a system of symbolic meanings in which self-presentation becomes an essential ingredient to produce the effect of horror. At the same time, the presence of such elements address a political dimension in the form of an allegory of
\end{abstract}


historical situations that could not be openly talked about or that could be explained more effectively if transported into a fantasy world. Mojica takes advantage of the fact that violence, torture and the representation of tyrannical forces in general are constitutive of the horror genre to give an aesthetic response to the society of his time in the form of a historical representation of the violent context of the Brazilian military dictatorship. This acclimatization of foreign elements inserted in the socio-cultural context of national productions constitutes what is called here "Brazilian Gothic".

Keywords

Zé do Caixão, José Mojica Marins, Gothic, Military Dictatorship in Brazil.

A partir de temas, imágenes y discursos se busca aquí una asociación entre el personaje de las películas brasileñas, Zé do Caixão (Pepe Ataúd/Coffin Joe), y un tipo específico de narrativa o imaginario sombrío, de origen anglo-americano, que se hizo conocido como gótico. Observando la dinámica de intercambios y apropiaciones culturales se busca demostrar cómo el director José Mojica Marins ${ }^{1}$ se vale de objetos escénicos, ángulos de cámara, iluminación, y figurines victorianos para elaborar una atmósfera que remite a la mise-en-scène de las películas expresionistas y clásicos de terror de Hollywood. Tales conjuntos de representación son esenciales para la creación de una tensión visual sin la cual las películas de Zé do Caixão difícilmente podrían ser consideradas pertenecientes al género de terror. La aclimatación de estos elementos extranjeros en el contexto sociocultural de Brasil constituye lo que aquí se define como «gótico brasileño».

Atrapado en algún lugar entre imitación y diferencia, interpretar las películas del personaje Zé do Caixão a la luz del gótico significa abordar el tema de la construcción de significado en la historia de Brasil: con potencial de revivir viejos traumas y provocar discusiones sobre contextos sociales específicos. En diálogo con tradiciones locales, las películas del personaje brasileño están marcadas por una dimensión nacional que se manifiesta en el contenido y en la

${ }^{1}$ José Mojica Marins es un productor, actor, director y cineasta independiente de São Paulo. Mojica, como es conocido en Brasil, afirma haber nacido en un viernes 13 (fecha que se ha convertido casi folclórica) de marzo de 1936. Se crió en el barrio Brás durante el Estado Novo (1937-1945), período de agitación política y malestar social en el país, y, consolidó su carrera cinematográfica durante el régimen militar (1964-1985). 
forma de las películas, poniendo en juego la cuestión de la brutalidad del régimen militar en Brasil (1964-1985). La presencia de elementos góticos en las películas sugiere un desplazamiento de ideas, expresados en una tentativa de situar las películas brasileñas en un imaginario típico del género de terror, una forma de abordar coyunturas históricas que no podían resolverse fácilmente o que podían ser discutidas con mayor eficacia si fueran transportadas a un mundo de fantasía.

Debido al discurso socio-ideológico promovido por la generación de "Cinema Novo", que influenció fuertemente la comprensión y estudio del cine brasileño, Mojica sufrió con el estigma social de ser un artista influenciado por los productos culturales estadounidenses, en particular, el cine y los cómics de aventuras, terror y misterio (Serravalle de Sá 174-218). Paradójicamente, a pesar de que no se creía que sus películas tenian contenido político, Mojica fue uno de los cineastas más censurados por la dictadura militar (Senador 1-9, Serravalle de Sá 156-173).

\section{Auto-referencialidad y multimedios: una breve trayectoria de José Mojica Marins}

Mojica debutó como director en la década de 1950, con las películas Sentença de Deus (Juicio de Dios 1954), Sina de um aventureiro (Sino de un aventureiro 1958) у Meu Destino em suas mãos (Mi destino en sus manos 1963), que, a pesar de los títulos exuberantes, no alcanzaron éxito comercial. El punto de inflexión en la carrera viene con la producción de À meia noite levarei sua alma (A medianoche me llevaré tu alma 1964), película en que aparece por primera vez su creación de mayor éxito: el personaje Zé do Caixão, cuyas anécdotas afirman que fue inspirado en una pesadilla: 
Tuve un sueño horrible y deliraba. Yo era como un ser poseído por el diablo. Vi a un hombre extraño vestido de negro arrastrándome a un acantilado o para algún lugar que no quería ir. Grité, pero el hombre de negro me arrastró a un cementerio, a una lápida con mi nombre y la fecha de mi muerte. Entonces vi que el hombre era yo - yo, ¡arrastrándome a mi propia tumba! yo no quería ver la fecha de mi muerte. Grité y grité mucho tiempo, y toda la familia de mi mujer fue a ver cómo estaba. ${ }^{2}$ (Higuchi 7)

El sepulturero profano, de las uñas largas, sombrero y capa de color negro, se convirtió en un icono del horror nacional, habiendo sido adaptado de las películas para diferentes medios de comunicación a ejemplo de programas de radio y televisión, cómics y literatura de cordel. ${ }^{3}$ Obsesionado con el universo sobrenatural y movido por el deseo de tener el hijo perfecto, Zé do Caixão es el protagonista de la trilogía que comienza con À meia noite levarei sua alma, tiene secuencia en Esta noite encarnarei no teu cadáver (Esta noche encarnaré en tu cuerpo 1968) y se completa solamente cuarenta años más tarde con Encarnação do demônio (Encarnación del diablo 2008).

El sepulturero también aparece en el cortometraje Ideologia (Ideología 1968) y en los largo-metrajes $O$ despertar da Besta / Ritual dos sádicos (Despertar de la Bestia tcc Ritual de sádicos 1970) y Delírios de um anormal (Confesiones de un anormal 1978), películas en que él no es el elemento central, pero donde hace apariciones especiales que confieren un grado de extrañeza a las

\footnotetext{
${ }^{2}$ En el original: «I had a horrible dream and was delirious. I was like being possessed by the devil. I saw a strange man in black dragging me to a cliff, or to some place I didn't want to go. I yelled, but the man in black dragged me to a graveyard, to a tombstone with my name and the date of my death. Then I saw the man was myself - me, dragging myself to my own grave! I didn't want to see the date of my death. I screamed and screamed for a long time, and my wife's entire family came to check on me».

${ }^{3}$ La literatura de cordel es un tipo de poesía escrita en forma de rima y ilustrada con xilografías. Fueron típicas en España y Portugal durante el período medieval y depués tuvieron mayor éxito aún en Brasil. Es así llamada por la forma como son vendidos los folletos, colgados en cordones (cordón).
} 
películas. En esta última, Zé do Caixão atormenta los sueños de un psiquiatra llamado Hamilton, que cree que el sepulturero aparecerá para secuestrar a su esposa. Los colegas del psiquiatra constituyen una junta médica y deciden que la mejor solución es llamar al propio cineasta para explicar que Zé do Caixão es un personaje ficticio inventado por él.

Hay dos puntos que cabe señalar aquí: primeramente, debe observarse cómo ocurre un engrandecimiento del personaje con el pasar de los años, que de un simple sepulturero de una pequeña ciudad en el interior de Brasil se convierte en una entidad maligna que aterroriza los sueños de los demás. Además, destaca como el propio cineasta se convierte en un personaje y, como objeto de discurso, hace uso de auto-referencialidad para nombrar su propio trabajo en varias escenas de la película, insiriendo de fragmentos de otras de sus películas, filmaciones de sus apariciones en televisión y mostrando gente que lee cómics de Zé do Caixão.

Tales meta-representaciones y escenas de auto-parodia destacan, doblemente, la presencia del personaje en diferentes medios de comunicación y la presencia del director Mojica que circula en esas dimensiones artísticas, caracterizando una situación que confunde a la gente acerca de la naturaleza de las respectivas identidades y cuestiona los límites entre creador y criatura.

\section{Zé do Caixão y el gótico}

Zé do Caixão es uno de los villanos más despiadados del cine de terror de la década de 1960, comparable a los más brutales asesinos en serie de su generación como Norman Bates (Psycho 1960), Mark Lewis (Peeping Tom 1960)

y Fuad Ramsés (Blood Feast 1963). La representación de agresividad del personaje brasileño se transmite mediante el uso de primeros planos, y muestra un nivel de brutalidad visual que no era familiar para el público de Brasil en los años 60; siendo igual o incluso superior a la representación de la violencia en la 
mayoría de las películas de terror anglo-estadounidenses producidas en el mismo período. Aunque se puede comparar Zé do Caixão con los principales asesinos en serie de los años 60, esos personajes que han renovado el repertorio clásico (sobrenatural) del género de terror, inaugurando la película de terror de la era moderna, él aún conserva la imagen y el comportamiento de un villano gótico.

Hay varias posibilidades de conexión entre las películas de Zé do Caixão y el gótico, entre ellas a través de una mise-en-scène que hace uso de rodajes en blanco y negro, iluminación monocromática, utilización de objetos no-realistas (cráneos de yeso, piedras hechas de espuma de polietileno, escenarios pintados) que hace referencia al aspecto fantasmal de un tipo de película que estudiosos del cine como Carlos Clarens y Heidi Kaye llaman gótico.

Algunas características o estilizaciones asociadas con el traje de Zé do Caixão son utilizadas por Mojica para establecer una conexión entre el personaje y la tradición gótica de películas de terror: sombrero de copa, capote negro, las uñas largas como garras. Sepulturero de un pequeño pueblo en el interior de Brasil, Zé do Caixão es una figura ajena a su lugar y tiempo, con ropa que se asemeja a la moda de lujo de la Inglaterra victoriana - remitiendo a personajes del cine clásico de los años 30, como Mr Hyde y Jack el destripador.

Sarah Street afirma que el traje es un elemento central de la identidad de los personajes, no el cuerpo. Según la crítica, «los trajes masculinos son reveladores acerca de la representación sartorial de estatus, dinero y estilo» (4). ${ }^{4}$ John Harvey observa que el color negro tiene connotaciones particulares que apuntan a una asociación entre ropas de color negro y hombres influyentes: «solo o en filas militares, el hombre de negro es un agente de enormes poderes» $(257){ }^{5}$

De hecho, el traje es un aspecto importante en la composición de Zé do Caixão, utilizado para el engrandecimiento del cuerpo. Inclusive, se puede decir que el personaje no sería tan marcante sin su traje suntuoso, que excede no sólo la

\footnotetext{
${ }^{4}$ En el original: that «male costumes are revealing about the sartorial representation of status, money and style».

${ }^{5}$ En el original: «alone or in the ranks, the man in black is the agent of serious power».
} 
posición social del personaje sino también los requisitos de la historia ambientada en una pequeña ciudad brasileña. La noción de estatus social, dinero, y estilo que el traje típicamente inglés de Zé do Caixão quiere transmitir no se encuentra en otros personajes de la película. Aquí, la exactitud socio-histórica es desconsiderada para se pueda ofrecer un espectáculo cinematográfico. Como elemento de performance, el vestuario del personaje se refiere a un sistema de significados simbólicos en que la auto-presentación se convierte en un ingrediente esencial para producir el efecto de terror. Mojica sabe que este traje victoriano está intrínsecamente ligado a la mecánica de producción de películas de terror.

O sea, mediante la observación del traje extranjero del personaje, el público lo asigna de inmediato a una serie de renombrados iconos de terror Mojica ha declarado su admiración por Bela Lugosi, Boris Karloff y Lon Chaney en entrevistas. Entonces, la referencia a tal repertorio iconográfico es un método de asignación de Zé do Caixão dentro del género de terror. Por otro lado, tal traje llamativo, exagerado y excesivo puede ser visto como una expresión humorística que habla de la incapacidad brasileña de imitar las películas extranjeras. Sería así una marca de las limitaciones económicas inscritas en la película, una precariedad de la producción que se muestra también en las imágenes granuladas de la película, en los ruidos ocasionales que interfieren con el sonido, todo lo cual habla de la pobreza y de las dificultades de producción de películas en Brasil. Aquí tenemos las mismas razones para la precariedad que se identifican en otras películas brasileñas de la época: dificultades financieras, falta de productores, falta de infraestructura adecuada, falta de mano de obra calificada.

Entonces, el traje de lujo es al mismo tiempo una forma de capitalizar sobre el éxito de películas de terror internacionalmente famosas, un homenaje al estilo clásico de terror que Mojica prefiere, como también una forma, intencional o no, de mostrar las marcas de las limitaciones económicas del país. 
CATEdral TomadA: Revista de crítica literaria latinoamericana / Journal of Latin American Literary Criticism Zé Do Caixão y el gótico brasileño de José Mojica Marins

\section{Ideologia (1968)}

El cortometraje «Ideologia» forma parte de la película $O$ Estranho Mundo de Zé do Caixão (1968), que contiene otros dos cortometrajes: O Fabricante de Bonecas (El fabricante de muñecas) e Tara (Fetiche), todos con guiones de Rubens Luchetti. En «Ideologia», el excéntrico professor-filósofo Oãxiac Odéz (anagrama de Zé do Caixão) trata de probar a un rival que el instinto prevalece sobre la razón, utilizando métodos poco ortodoxos: asesinatos, violaciones, necrofilia y antropofagia. Vistiendo una capa negra y con las uñas largas, amenazadoramente curvadas como garras (ejemplos del gótico), Oãxiac Odéz da una entrevista en vivo en la televisión para explicar sus teorías sobre la naturaleza humana y la superioridad del instinto sobre la razón. Los reporteros y polemistas, algunos enojados, otros no tanto, interrogan, pelo el profesor responde con frases crípticas y con las comparaciones más extrañas posibles. Cuando termina el programa, uno de los reporteros acepta la invitación Odéz para una cena en su casa, que irá culminar en un banquete de carne humana. La película fue lanzada el mismo año del quinto Ato Institucional (AI-5), documento que suspendió derechos sociales y jurídicos de los brasileños. Incluso, la película sólo se liberó después de negociaciones con el Servicio de Censura de Espectáculos Públicos (SCDP).

En «Ideologia», esta palabra simbólica para aquel momento, la realidad socio-histórica del país aparece como una virtualización de los significados. Lo que se ve son detenciones arbitrarias, tortura, ejecuciones a sangre fría, destrucción/desaparición de cuerpos y otras brutalidades que eran cometidas durante el gobierno militar. Son referencias que permiten que el público pueda hacer un enlace entre el texto cinematográfico y el contexto histórico, sugiriendo ese potencial metafórico o alegórico.

Douglas Kellner afirma que las «películas llevan la materia prima de la historia y el discurso social y los procesan en productos que son ellos mismos 
acontecimientos históricos y fuerzas sociales» (355). ${ }^{6}$ Kellner está reconociendo que las películas pueden generar subtextos socio-históricos por medio de procesos de sustitución metafórica. Estos enlaces entre lo real y lo ficticio a menudo encuentran expresión retórica en forma de la alegoría (que aquí se entiende como una virtualización de los significados).

Ismail Xavier analiza la alegoría histórica en cuanto característica de algunas películas y explica por qué esta ha sido una forma de interpretación privilegiada en determinados momentos históricos. Él afirma que «el reconocimiento de una dimensión alegórica en un texto requiere la capacidad de percibir homologías y alegorías nacionales requieren la comprensión de la vida privada como representante de los destinos públicos» (335). Xavier también sugiere que la expresión alegórica es especialmente frecuente en tiempos de represión política y sirve como medio de ofrecer un «comentario encubierto sobre el presente» $(354){ }^{7}$

La identificación de alegorías nacionales requiere emparejar circunstancias específicas del texto y del contexto histórico, proporcionando comentarios disfrazados sobre la realidad. Aunque el enfoque histórico ha sido cuestionado por los enfoques postestructuralistas, pocos negarían que es posible discernir en obras de arte cuestiones que fueron importantes en un determinado momento de la historia de una nación. Obviamente no todas las películas o las películas de terror son alegóricas, pero eso no quiere decir que no presenten un aspecto histórico.

En «Ideologia», Mojica recrea inúmeras bestialidades practicadas en las casas del terror del gobierno militar. Entre algunas conocidas técnicas para infligir daño físico a los detenidos había: paliza y violación (los agresores utilizan sus cuerpos y objetos para penetrar la víctima), tortura utilizando insectos y animales, estrangulación y ahogamiento. El director se atreve a representar escenas de

${ }^{6}$ En el original: «films take the raw material of social history and of social discourses and process them into products which are themselves historical events and social forces».

${ }^{7}$ En el original: «disguised comment on the present». 
tortura que, debido a la censura de la prensa, se mantuvieron lejos de los ojos públicos, pero habitaban la imaginación de muchos brasileños. Entonces, lo que se tiene es una muestra del contexto violento del régimen militar en forma de una película de terror. En otras palabras, el director escenifica o reproduce en la película actos de tortura y violencia bajo el pretexto de ser solamente una película de terror.

Mojica promueve un desplazamiento de ideas como una forma de discutir temas que no podrían ser discutidos abiertamente o que tal vez podrían ser mejor comprendidos si fuesen transportados a un mundo ficcional de horror y fantasía, donde reconocer una determinada situación tal vez se hace más fácil. El director se aprovecha del hecho de que la violencia, la tortura y la representación de las fuerzas tiránicas son constitutivas del género de terror y da una respuesta estética a la sociedad de su tiempo en forma de una representación histórica del contexto violento de la dictadura militar brasileña.

Mediante la fusión entre ficción y contexto histórico, Mojica y Zé do Caixão adentran nuevamente el universo gótico, ahora más allá de los rasgos estilizados, porque, como ya fue debatido por críticos como Victor Sage y David Punter, la ficción gótica surge en tiempos de crisis, siendo el subtexto políticosocial algo inherente al gótico. Es también en este sentido que el personaje Zé do Caixão se convierte en un villano gótico por derecho propio, un gótico brasileño.

Por esta audacia Mojica pagó caro. Fue perseguido por los organismos de control del Estado y sus películas fueron censuradas, es el cineasta que más sufrió con la censura en la historia del cine brasileño. Mojica podría haberse defendido diciendo que temas como violencia, tortura y tiranía son constitutivos del género de terror-gótico, pero, si lo hizo, el argumento no fue suficiente para evitar la censura de sus películas.

En algunas entrevistas con el cineasta se pueden leer declaraciones en que Mojica niega este contexto sociopolítico. ¿Qué pasa cuando el autor niega? Son varias las razones para que él niegue esta interpretación: El miedo de algún tipo de represalia, aunque la dictadura haya terminado desde 1985. O él no está 
interesado en esta asociación política (tal vez la deje para el Cinema Novo). Mojica puede creer que tal asociación sea reduccionista y tome el valor de entretenimiento de sus películas. Pero aun así se mantiene aquí la lectura política, porque a veces el significado de la obra supera las intenciones del autor.

Mojica no hizo el Drácula de Brasil, el hombre lobo del Amazonas o el Frankenstein en Río de Janeiro, sino un personaje brasileño con elementos nacionales. No recurre a maldiciones antiguas, países exóticos, monstruos, extraterrestres o amenazas extranjeras a fin de crear terror. Es decir que no desplaza ansiedades nacionales en el tiempo y el espacio o proyecta el horror sobre el otro. Sus películas se establecen dentro de una dimensión nacional y están llenas de referencias nacionales. Se puede decir que es un cineasta «del pueblo» porque su principal tema son los brasileños. En este sentido, su trabajo y uso de la adaptación de elementos del terror de origen anglo-americano ocurre de modo diferente de Mario Bava, Dario Argento, Jess Franco, pensando términos de «color local» y contextos sociopolíticos nacionales.

El terror gótico que Mojica propone es un terror palpable, un terrorpesadilla, aquel de no ser capaz de confiar en la persona a tu lado, de despertar con arañas y serpientes encima. En el más puro estilo gótico tropical, Mojica hace uso sin precedentes de animales típicos de Brasil. Zé do Caixão es esta presencia dominante que impone su voluntad sobre la gente común, un personaje que se burla de su público, despreciando la religión y las creencias nacionales y exponiendo la apatía del pueblo de cara a la injusticia y las estructuras de poder. En sus películas existe una preocupación acerca de las fuerzas que amenazan a los individuos, los grupos, y la vida social en general. Es un personaje que expone el funcionamiento del poder y la represión.

Cuando se trata de la realidad brasileña, el terror de Zé do Caixão es más inquietante que cualquier monstruo Drácula, Frankenstein o momia podría ser. Como Vinícius de Moraes señala, estos personajes de Hollywood son considerados un tanto extraños en Brasil, ya que «tienen poca relación con la 
realidad nacional» (243). ${ }^{8}$ Con el empeoramiento de la situación política en Brasil, la representación alegórica de violencia, tortura, fuerzas tiránicas, era una manera de utilizar el género de terror a escala para discutir los problemas de esa sociedad. Zé do Caixão es un representante del gótico tropical, tan inquietante como Frankenstein, Drácula, o la momia podrían ser.

Los años 60 fueron en muchos sentidos el punto culminante de Zé do Caixão en el cine, puesto que en las décadas siguientes la censura condenó Mojica al ostracismo y casi acabó con su carrera. En los años 70 y 80 sobrevivió como cineasta en la industria del porno. Bajo el seudónimo J. Avelar hizo películas como $24 h$ de Sexo Ardente (24 horas de sexo ardiente) y $48 h$ de Sexo Explícito (48 horas de sexo explícito) esta última contiene la primera escena de bestialidad del cine brasileño. Durante ese periodo, Mojica también animaba fiestas en los suburbios de São Paulo, de heraldo del terror pasó a payaso de circo de horrores. En los años 90, vuelve a la televisión con un programa en canal Bandeirantes llamado cine trash, al estilo de Tales of the Crypt.

\section{Conclusión}

Debido al discurso ideológico promovido por la generación de Cinema Novo, a lo largo de su historia Mojica sufrió el estigma social de ser un artista influenciado por los productos culturales estadounidenses, en particular, el cine y los cómics de aventuras, terror y misterio. Paradójicamente, a pesar de que sus películas son consideradas desprovistas de contenido político, Mojica fue quizás uno de los cineastas más censurados por la dictadura militar.

Esa lectura actúa como un correctivo a interpretaciones anteriores al buscar demostrar cómo Mojica hace uso de un conjunto de representaciones asociadas con el gótico (trajes, ángulos de cámara, iluminación, accesorios) con el

\footnotetext{
${ }^{8}$ En el original: «têm pouca relação com a realidade nacional».
} 
objetivo de destacar el problema de la brutalidad del estado militar. La mise-enscène gótica se refiere a un sistema de significados simbólicos en que la autopresentación se convierte en un ingrediente esencial para producir el efecto de terror. Si, por un lado, tal estrategia ayuda al público a asociar las películas de Zé do Caixão con una serie de renombrados iconos y películas de terror angloamericanas, por otro lado, eso puede ser interpretado como una incapacidad de imitar las producciones extranjeras (las limitaciones económicas y dificultades de producción de cine en Brasil). Zé do Caixão sería un antagonista que se sitúa entre los villanos góticos clásicos de Hollywood y asesinos en serie de películas modernas. A pesar de las referencias extranjeras, se defendió que tales elementos son resignificados y que sus películas presentan un tipo de terror que habla de valores culturales brasileños. Se pueden leer tales características en la forma de la película, incluyendo las imágenes granuladas, los ruidos en la banda sonora, en las soluciones creativas para resolver el problema de la precariedad en la producción de cine en Brasil.

A partir de una dinámica de intercambios y apropiaciones culturales, se destacaron aquí elementos teóricos y temáticos que buscan situar a las películas de Zé do Caixão dentro de un imaginario típico de las películas de terror, más particularmente un imaginario narrativo que se hizo conocido como gótico. La presencia de tales elementos góticos, al mismo tiempo que evidencia la presencia de una dimensión política también sugiere un cambio de ideas, una forma de alegorización de situaciones históricas que no podían ser fácilmente comprendidas o que podrían abordarse con mayor eficacia si fuesen transportadas a un mundo de fantasía. La aclimatación de elementos extranjeros insertada en el contexto socio-cultural de las producciones constituye lo que se llamó aquí «gótico brasileño».

El vínculo entre violencia y dictadura en las películas de terror de José Mojica Marins, las imágenes flagrantes de brutalidad y tortura en la pantalla, se intensifican al paso que la represión social aumenta en la vida real. Se resaltó aquí como el cortometraje «Ideologia» evidencia la realidad socio-histórica del país 
poniendo en escena detenciones arbitrarias, tortura, las ejecuciones a sangre fría, desaparición de los cuerpos y otras brutalidades cometidas durante el gobierno militar brasileño. Las técnicas militares para infligir daño físico a los detenidos eran bien conocidas por el público y permiten que se haga un enlace entre la película y el contexto histórico.

Mojica pone en escena actos de tortura y violencia que debido a la censura de la prensa se mantuvieron lejos de los ojos públicos, pero habitaban la imaginación de muchos brasileños. El resultado es una muestra del contexto violento del régimen militar en forma de una película de terror que promueve un desplazamiento de ideas como una forma de discutir temas que no podrían ser discutidos abiertamente, cuestiones no podían ser abordadas directamente en el momento en que fueron trasladadas a la esfera las películas del género de terror. En esencia, la cuestión del «poder» subyace a las películas del personaje Zé do Caixão, puesto que existe una preocupación central acerca de las fuerzas que amenazan a los individuos, los grupos y la vida social en general. Zé do Caixão es tanto un rebelde como un torturador, el personaje expone el funcionamiento del poder y de la represión que se desarrolló históricamente en respuesta a cambios políticos y sociales. Así, a través de la fusión entre ficción y contexto histórico, Mojica y Zé do Caixão pueden ser relacionados a la tradición gótica, ahora más allá de los rasgos estilizados, como el traje victoriano. Los contextos y subtextos político-sociales son inherente al gótico, de modo que el personaje brasileño Zé do Caixão se convierte en un villano gótico por derecho propio.

La evaluación crítica internacional de Mojica lo ha comparado a directores como Ed Wood, Mario Bava, Buñuel y Terence Fisher. Los críticos Randal Johnson y Robert Stam declaran que Mojica seria «la respuesta del Brasil a George Romero, experto en un tipo de subgénero caníbal de la película de terror» $(9)^{9}$ - pero la primera película de Zé do Caixão apareció cuatro años antes de The Night of the Living Dead (La noche de los muertos vivientes 1968), lanzada en el

${ }^{9}$ En el original: «Brazil’s answer to George Romero, a specialist in a kind of cannibalistic subgenre of the horror film». 
mismo año de la segunda película de Zé do Caixão. Las películas de Mojica son elementos culturales multifacéticos y pueden ser leídas en diferentes niveles y modos, no apenas relacionados con la historia de Brasil. Aquí se entienden tales comparaciones como una cortesía para el público que no ha visto antes las películas de Mojica. Cuando los críticos resaltan el trabajo de Mojica a la luz de producciones de renombre, la intención es despertar el interés del espectador asociando su cine a otras producciones más conocidas y reconocidas, o sea colocar Mojica dentro de un repertorio mundial. Las películas de Mojica son técnicamente modestas pero extrañamente fascinantes, están llenas de imágenes fuertes que implican escenas de sadismo, gore, desnudez y surrealismo. El contraste entre la mise-en-scène rudimentaria y artesanal y la audacia de los temas e imágenes ofrece películas originales y memorables, con momentos de gran habilidad detrás de la cámara. Son películas que perduran en la mente de los

espectadores $\mathrm{y}$, sin duda, sirven para repensar lo que debe considerarse vanguardia en las películas de terror de las décadas de 1960 y 1970.

\section{Bibliografía}

Clarens, Carlos. An Illustrated History of the Horror Film. Putnam, 1967.

Harvey, John. Men in Black. Reaktion, 1995.

Higuchi, Horácio. “José Mojica Marins: the madness in his method.” Monster! International, no. 3, October 1993, pp. 5-35.

Johnson, Randall \& Robert Stam, editors. Brazilian Cinema. University of Texas Press, 1988.

Kaye, Heidi. "Gothic Film.” A Companion to the Gothic, edited by David Punter, Wiley-Blackwell, 2001, pp. 180-192. 
CATEdral TomadA: Revista de crítica literaria latinoamericana / Journal of Latin American Literary Criticism Zé Do Caixão y el gótico brasileño de José Mojica Marins

Kellner, Douglas. "Hollywood film and society." The Oxford Guide to Film Studies, edited by J. Hill \& P.C. Gibson, Oxford University Press, 1998, pp. 354-364.

Mojica Marins, José, director. Coleção Zé do Caixão: 50 anos do Cinema de José Mojica Marins, DVD collection, vol. 1 - 5, Cinemagia, 2002.

Moraes, Vinícius de. O Cinema de Meus Olhos, edited by C.A. Calil, Companhia das Letras, 1991.

Sage, Victor. The Gothick Novel, a casebook. Macmillan, 1990.

Senador, Daniela Pinto. "A intervenção da censura no filme Esta noite encarnarei no teu cadáver (1967) de José Mojica Marins." XVIII Encontro Regional de História - O historiador e seu tempo, CD-ROM, ANPUH/SP UNESP/Assis, 2006, pp.1-9.

Serravalle de Sá, Daniel. Brazilian horror: Zé Do Caixão in the multimedia work of José Mojica Marins. PhD thesis, The University of Manchester, 2010.

Street, Sarah. Costume and Cinema: Dress Codes in Popular Film. Wallflower, 2001.

Punter, David. The Literature of Terror: a History of Gothic Fictions from 1765 to the Present Day. Longman, 1996.

Xavier, Ismail. "Historical allegory." A Companion to Film Theory, edited by T. Miller \& R. Stam, Blackwell, 1986, pp. 333-362. . Allegories of Underdevelopment: Aesthetics and Politics in Modern Brazilian Cinema. University of Minnesota Press, 1997 